Gut and Liver, Vol. 11, No. 6, November 2017, pp. 761-770

REVIEW

\title{
Familial Pancreatic Cancer and the Future of Directed Screening
}

\author{
Sara Welinsky ${ }^{1}$ and Aimee L. Lucas ${ }^{1,2}$ \\ ${ }^{1}$ Samuel F. Bronfman Department of Medicine and ${ }^{2}$ Henry D. Janowitz Division of Gastroenterology, Icahn School of Medicine at Mount Sinai, \\ New York, NY, USA
}

Pancreatic cancer (PC) is the third most common cause of cancer-related death in the United States and the 12th most common worldwide. Mortality is high, largely due to late stage of presentation and suboptimal treatment regimens. Approximately $10 \%$ of PC cases have a familial basis. The major genetic defect has yet to be identified but may be inherited by an autosomal dominant pattern with reduced penetrance. Several known hereditary syndromes or genes are associated with an increased risk of developing PC and account for approximately $2 \%$ of PCs. These syndromes include the hereditary breast-ovarian cancer syndrome, PeutzJeghers syndrome, familial atypical multiple mole melanoma, Lynch syndrome, familial polyposis, ataxia-telangiectasia, and hereditary pancreatitis. Appropriate screening using methods such as biomarkers or imaging, with endoscopic ultrasound and magnetic resonance imaging, may assist in the early detection of neoplastic lesions in the high-risk population. If these lesions are detected and treated before the development of invasive carcinoma, PC disease morbidity and mortality may be improved. This review will focus on familial PC and other hereditary syndromes implicated in the increased risk of PC; it will also highlight current screening methods and the future of new screening modalities. (Gut Liver 2017;11:761-770)

Key Words: Pancreatic neoplasms; Familial pancreatic cancer; Mass screening; High-risk

\section{INTRODUCTION}

Pancreatic cancer (PC) is the third most common cause of death from cancer in the United States and the 12th most common cancer related death worldwide. ${ }^{1}$ There were an estimated 49,000 new diagnoses and over 41,000 associated deaths in the
United State in 2015 with over 227,000 deaths per year worldwide. $^{2,3}$ The majority (96\%) are cancers that arise from the exocrine pancreas. ${ }^{3}$ Although diagnostic accuracy and treatments have improved, the survival rates remain dismal with an average 5-year survival of 7\%, which can be attributed to the characteristically late stage of the disease at the time of diagnosis. ${ }^{3}$ Both environmental and genetic risk factors contribute to the disease. PC often develops in three settings: sporadic PC, familial pancreatic cancer (FPC), and inherited cancer syndromes (Fig. 1). ${ }^{4,5}$ Several reports have estimated that up to $10 \%$ of PC cases have a familial basis. ${ }^{4,6}$ This review will focus on the overview of PC with an emphasis on FPC including risk factors, high-risk screening methods and new screening modalities.

\section{PANCREATIC CANCER STAGING AND PROGNOSIS}

The survival rates of PC are disappointing with 1-year and 5-year survival rates of 29\% and 7\%, respectively. ${ }^{3}$ This is in large part due to the lack of symptoms associated with early

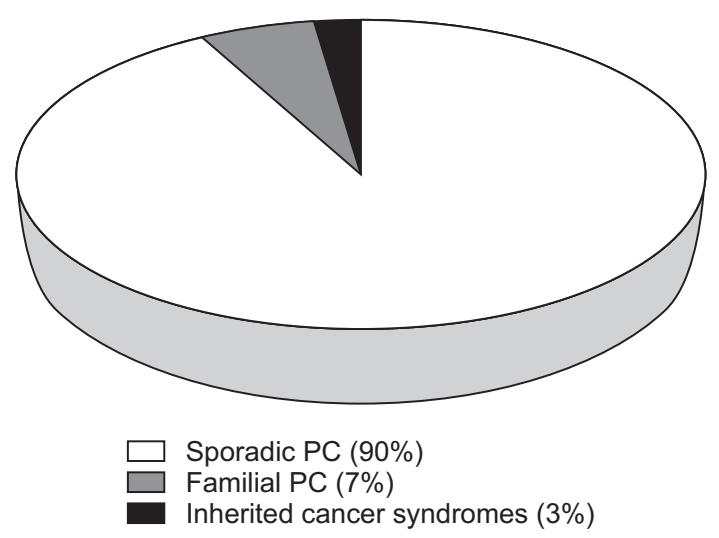

Fig. 1. Proportions of pancreatic cancer (PC) due to inherited factors.

\footnotetext{
Correspondence to: Aimee L. Lucas

Henry D. Janowitz Division of Gastroenterology, Icahn School of Medicine at Mount Sinai, 1 Gustave L. Levy Place, Box 1069, New York, NY 10029, USA

Tel: +1-212-241-0101, Fax: +1-646-537-8647, E-mail: aimee.lucas@mssm.edu

Received on August 20, 2016. Revised on November 1, 2016. Accepted on November 1, 2016. Published online June 15, 2017 pISSN 1976-2283 eISSN 2005-1212 https://doi.org/10.5009/gnl16414

@ This is an Open Access article distributed under the terms of the Creative Commons Attribution Non-Commercial License (http://creativecommons.org/licenses/by-nc/4.0) which permits unrestricted non-commercial use, distribution, and reproduction in any medium, provided the original work is properly cited.
} 
stages of PC. Patients often present at later stages with weight loss, abdominal discomfort and jaundice. ${ }^{3}$ Surgical resection is the only curative treatment for PC. ${ }^{7}$ However, less than 20\% of patients are surgical candidates at the time of presentation and the median survival of nonresected patients is 3.5 months. ${ }^{8}$ Even those patients who are candidates for surgery have a median survival of 12.6 months. ${ }^{8}$ The absence of symptoms until advanced stages of disease underscores the importance of early detection, both through identification of high-risk individuals and high-risk precursor lesions.

\section{HEREDITARY PANCREATIC CANCER SYNDROMES}

Identification of individuals at high-risk of PC based on family history or germline genetic mutations may allow for early detection and therapy. Hereditary pancreatic cancer syndromes include: hereditary breast-ovarian cancer (HBOC), Peutz-Jeghers syndrome, familial atypical multiple mole melanoma (FAMMM), Lynch syndrome (or hereditary nonpolyposis colorectal carcinoma [HNPCC]), familial adenomatous polyposis (FAP), ataxiatelangiectasia (ATM), and hereditary pancreatitis (HP). These hereditary cancer syndromes account for approximately 10\% to 15\% of hereditary PC cases (Table 1). The genetic etiology of the majority of FPC has yet to be identified. ${ }^{4}$

\section{FAMILIAL PANCREATIC CANCER}

Hereditary PC syndromes only explain a fraction of the clusters of familial based trends. The term FPC applies to families with two or more first-degree relatives (FDRs) with PC that do not fulfill the criteria of any other inherited tumor syndrome. ${ }^{9}$ FPC accounts for approximately $80 \%$ of PC clustering. ${ }^{6}$ When compared with the general population, the risk of developing PC in individuals with two FDRs has been estimated at 6.4-fold greater risk with a lifetime risk of $8 \%$ to $12 \%$; those with three FDRs have a remarkable 32-fold greater risk and a 40\% lifetime risk of developing PC. ${ }^{10}$ One study, using complex segregation analysis, suggested that a yet unidentified major autosomal dominant inherited gene with reduced penetrance could represent a high risk mutation found in FPC. ${ }^{11}$

A large European study investigated 106 FPC families and found that from one generation to the next, the age of death from PC was younger with each generation: a phenomenon known as anticipation. ${ }^{12}$ Subsequent studies performed by the European Registry of Hereditary Pancreatitis (EUROPAC) and German national case collection for FPC (FaPaCa) confirmed this phenomenon, showing an earlier development of PC by approximately 10 years in 59\% to $80 \%$ of FPC families. ${ }^{12,13}$

Hereditary breast-ovarian cancer (HBOC) syndrome and other Fanconi anemia genes are inclusive of BRCA1, BRCA2/FANCD1, PALB2/FANCN, FANCC, and FANCG. The HBOC syndrome represents early-onset breast and ovarian cancers stemming from germline mutations in BRCA1 and BRCA2 tumor suppressor genes. The Fanconi anemia genes have well-described involvement in multiple DNA repair mechanisms, one of which includes the BRCA1/BRCA2 pathway. ${ }^{14}$ BRCA2 mutations are the most frequently identified mutation in FPC, associated with a 3.5- to 10-fold increased risk of PC compared to the general population. ${ }^{15,16}$ The association between BRCA1 mutations and PC is less well defined but has been reported at an approximate 2.5 to 3 times increased risk. ${ }^{17,18}$ However, two studies found no link between BRCA1 mutation and PC. ${ }^{19,20}$ Partner and Localizer of BRCA2 (PALB2), also known as (FANCN), is a protein implicated in the nuclear localization and stability required for

Table 1. Cancer Syndromes and Genes Currently Associated with Pancreatic Cancer

\begin{tabular}{|c|c|c|c|}
\hline Syndrome & Gene & Lifetime risk of PC, \% & Other associated cancers \\
\hline Peutz-Jeghers syndrome & STK11/LKB1 & $11-36$ & $\begin{array}{l}\text { Esophagus, stomach, small intestine, } \\
\text { colon, breast, lung, ovary, uterus }\end{array}$ \\
\hline Familial atypical multiple mole melanoma & $p 16^{I N K 4 A}(C D K N 2 A$ or $M T S 1)$ & 17 & Melanoma \\
\hline \multirow[t]{4}{*}{ Hereditary breast cancer } & BRCA1 & Increased & Breast, ovarian \\
\hline & $B R C A 2$ & RR 3.5-5.9 & \\
\hline & PALB2 & Increased & \\
\hline & ATM & Increased & \\
\hline Lynch syndrome & HNPCC & 3.7 & $\begin{array}{l}\text { Colon, endometrium, ovary, stomach, } \\
\text { small intestine, urinary tract, brain, } \\
\text { cutaneous sebaceous glands }\end{array}$ \\
\hline Familial polyposis & $A P C$ & 1.7 & $\begin{array}{l}\text { Colon, medulloblastoma, papillary } \\
\text { thyroid carcinoma, hepatoblastoma, } \\
\text { desmoid tumors }\end{array}$ \\
\hline Hereditary pancreatitis & PRSS1 & $25-40$ & None \\
\hline
\end{tabular}

PC, pancreatic cancer; RR, relative risk. 
some functions of BRCA2. ${ }^{21}$ Its association with PC was first described using whole genome sequencing performed on FPC patients. PALB2 was postulated to be the second most commonly mutated gene in hereditary PC, accounting for $1 \%$ to $3 \%$ of FPC individuals ${ }^{22}$ and conferring up to 8.6-fold increased risk. ${ }^{23}$ However, these results have not been confirmed in other studies.

Peutz-Jeghers syndrome (PJS) is an autosomal dominant polyposis disease associated with an inherited mutation in the STK11/LKB1 tumor suppressor gene. ${ }^{24,25}$ The typical characteristics of this mutation are mucocutaneous pigmentations of the lips, buccal mucosa and periorbital areas. ${ }^{26}$ This germline mutation carries an increased risk of cancer with a cumulative risk for all cancers of 93\% from age 15 to 64 years. ${ }^{27}$ Multiple gastrointestinal cancers have been implicated, including gastric and small bowel adenocarcinoma but also nongastrointestinal cancers, such as breast, ovarian, endometrial, cervical and testicular cancers. ${ }^{27}$ PJS is associated with a 132 -fold ${ }^{27}$ increased risk of $\mathrm{PC}$ alone when compared to the general population, and a lifetime PC risk of $11 \%$ to $36 \%{ }^{25}$

Familial atypical multiple mole melanoma (FAMMM) is an autosomal dominant disorder of a germline mutation in $p 16^{I N K 4 A}$ (also known as CDKN2A or MTS1). This mutation is commonly known for atypical nevi and high-risk cutaneous malignant melanomas. ${ }^{28}$ The $p 16^{I N K 4 A}$ has been shown to function as a melanoma tumor-suppressor gene. Studies have confirmed this germline mutation of $p 16^{I N K 4 A}$ in some American, European and Australian melanoma-prone kindreds. ${ }^{29-31}$ Several studies also found increased risk of PC and referred to it as a separate syndrome called FAMMM pancreatic cancer (FAMMM-PC). Individuals with this syndrome have a relative risk of $20 \%$ to $34 \%$ for the development of PC, and an approximate lifetime risk of $17 \% .^{32}$

Lynch syndrome (or HNPCC) is the most common inherited colorectal cancer syndrome and is associated with multiple mutations in mismatch repair genes including MLH1, MSH2, MSH6, PMS2, and EPCAM. ${ }^{33}$ In addition to having a predisposition for cancers of the colon, endometrium, ovary, stomach, small intestines, urinary tract, brain and cutaneous sebaceous glands, individuals with mismatch repair mutations have a lifetime risk of 3.7\% for developing PC. ${ }^{33,34}$ There is little evidence to support isolated risk attributed to specific genotypes.

Familial adenomatous polyposis (FAP) is a colorectal cancer syndrome resulting from a mutation in the adenomatous polyposis $(A P C)$ gene causing hundreds of adenomatous colorectal polyps which if left untreated will inevitably lead to colorectal cancer. FAP syndrome is associated with a 4.5 -fold increase of developing PC and a lifetime risk of $1.7 \%$. $^{35}$

Ataxia-telangiectasia (ATM) is an autosomal recessive disorder characterized by progressive neurologic symptoms and resulting in a marked predisposition for cancer, particularly lymphoma and leukemia. ${ }^{36,37}$ Monoallelic mutations in the ATM gene, which is involved in DNA repair, confer an increased risk of cancer, particularly breast cancer in females. ${ }^{38}$ Monoallelic mutations in the ATM gene also result in at least twice the rate of PC compared with the general population. ${ }^{38}$ One study analyzed a FPC cohort of 166 patients and found that 2.4\% were monoallelic mutation carriers; this proportion increased to $4.6 \%$ with three or more affected family members. ${ }^{37}$

Hereditary pancreatitis (PRSS1) is a rare, autosomal dominant form of chronic pancreatitis which presents as repeated episodes of acute pancreatitis during childhood and adolescence resulting in chronic pancreatitis in early adulthood. ${ }^{39}$ A majority of HP is caused by germline mutation in PRSS1 which codes for the enzyme trypsinogen. ${ }^{40}$ PRSS 1 mutation carriers have increased risk of PC beginning in the fifth decade of life with a lifetime risk of $25 \%$ to $40 \%$ in comparison to the general population. ${ }^{41}$

Palladin (PALLD) was found to be overexpressed in a PC prone family and thought to predispose to FPC in an autosomal dominant fashion. ${ }^{42}$ After finding overexpression of $P A L L D$ mRNA in PC tissue, PALLD was postulated to be a proto-oncogene encoding for a component of the cytoskeleton responsible for cell shape and motility. ${ }^{42,43}$ Follow-up studies, including sequencing of the entire PC genome, have failed to identify somatic mutations in PALLD..$^{43-45}$ A postulated role of PALLD in FPC requires further investigation.

\section{IDENTIFICATION OF HIGH-RISK INDIVIDUALS}

The first step in identification of FPC is construction of a three-generation pedigree. Family members with a history of cancer are identified, and information such as age of onset, age of death, and tobacco exposure is noted. If multiple PCs are identified, or multiple cancers (particularly young onset cancers) are present, it is reasonable to consider FPC or a hereditary PC syndrome and place a referral to a genetic counselor. Previously, working with a genetic counselor meant identifying highrisk tendencies within a family including characteristics such as Ashkenazi Jewish heritage or clusters of breast and ovarian cancers, which might drive testing for specific germline mutations. With expanding capabilities for high-throughput DNA sequencing and declining costs, commercial panel tests for PC (including analysis of upwards of 13 genes) are now available and widely employed. ${ }^{46}$

Genetic testing may be most informative when affected family members are able to undergo gene testing. The high mortality rate and short survival time in PC often make this difficult. Additionally, since the genetic basis of the majority of FPC is not fully understood, the utility of genetic testing in the absence of testing an affected family member is often further diminished, and gene test results may be uninformative. Despite these limitations, future FPC management and screening will likely include genome sequencing as a part of standard management. When a hereditary PC syndrome is suspected, gene testing and DNA banking of affected family members should be encouraged 
soon after diagnosis so that other family members may make informed screening and management decisions. Multiple large academic centers offer risk stratification as described above, along with clinical genetic testing and research protocols that may include DNA banking.

\section{MODIFIABLE RISK FACTORS}

Risk factors such as tobacco use, obesity, heavy alcohol consumption, and diabetes mellitus (DM) have all been demonstrated to increase the risk of PC. ${ }^{3}$ These risk factors, although welldescribed, have not been extensively studied in hereditary PC.

Active cigarette smoking dramatically increases risk for PC with an incidence rate that is twice as high in smokers as in nonsmokers and this risk may be more pronounced in the FPC population. ${ }^{47}$ In subjects with at least one FDR with PC, the standardized incidence ratio (SIR) for PC in those with tobacco exposure was 19.2, compared with a SIR of 6.2 in nonsmokers. ${ }^{10}$ Smoking has also been shown to lower the age of onset of PC by 10 years. ${ }^{48}$ This risk is even higher among smokers with hereditary pancreatitis who tend to develop disease 20 years before nonsmokers. ${ }^{49}$ Heavy alcohol use ( $>3$ drinks per day) has been associated with a 1.22 -fold increased risk of PC. ${ }^{50}$ This may in part be explained by alcohol's effect on upregulating inflammatory pathways, which leads to pancreatitis and ultimately may result in necrosis and carcinogenesis. ${ }^{51}$

$\mathrm{DM}$, another well-known risk factor for $\mathrm{PC}$, has a prevalence in the PC population as high as $40 \% .^{52}$ The mechanism of PC development is not clearly understood in long standing DM but could be related to the cellular proliferative effect of hyperglycemia, hyperinsulinemia, and abnormalities in insulin receptor pathways including insulin growth factor, mammalian target of rapamycin or protein kinase B (AKT). ${ }^{53-55}$ New-onset DM has also been shown to be an early manifestation of PC known as type 3c, or pancreaticogenic, diabetes..$^{53}$ Therefore, there exists both a causal and consequential effect of DM on the development of PC. A meta-analysis of 36 studies showed that individuals who were recently diagnosed with DM within the last 4 years had a 50\% greater risk of malignancy compared with those who had DM for more than 5 years. ${ }^{56,57}$ Thus, recent development of DM may be a sign of otherwise asymptomatic PC. However, screening for PC in the setting of new-onset DM is not currently recommended.

\section{PANCREATIC CANCER PRECURSOR LESIONS}

Several PC precursor lesions have recognizable latent or early stages of disease. ${ }^{58}$ These lesions include pancreatic intraepithelial neoplasms (PanINs), intraductal papillary mucinous neoplasm (IPMNs) and mucinous cystic neoplasms (MCNs).

\section{PANCREATIC INTRAEPITHELIAL NEOPLASIA}

PanINs are microscopic noninvasive, small epithelial neoplasms. ${ }^{59}$ Grades of PanINs have been classically defined by degree of atypia: PanIN-1A (flat), PanIN-IB (papillary without dysplasia), PanIN-2 (papillary with dysplastic changes), and PanIN-3 (carcinoma in situ). ${ }^{60}$ In 2015, revised recommendations for classification uses a two-tiered system of low-grade and high-grade lesions. ${ }^{61}$ PanIN-2 and PanIN-3 lesions are precursors of invasive PC in patients with both sporadic PC and FPC, yet the frequency and rate at which they progress to invasive cancer is unknown. ${ }^{62}$ It may take a decade or more for an early PanIN to progress to invasive cancer. ${ }^{63}$ This presents a challenge for screening, making it difficult to establish an appropriate window for early detection. One study investigated pancreatic tissue after surgical removal and found 82\% of invasive cancer specimens harbored PanIN lesions compared to just 28\% in normal samples. ${ }^{64}$ While there is a well-established association between PanIN lesions and invasive cancer, autopsy studies have identified PanIN lesions in the pancreata of up to $48 \%$ of healthy controls indicating that not all PanIN lesions progress to PC. ${ }^{65,66}$ Furthermore, the frequency of PanIN lesions increases when comparing normal pancreata to pancreatitis to ductal adenocarcinoma (16\%, 60\%, and 82\%), respectively. ${ }^{64}$ Since PanIN-1 lesions likely confer little risk and PanIN-3 lesions greater risk, identification of higher grade indicates neoplastic potential and would be a target of interest in a screening and surveillance program. ${ }^{62}$ PanIN lesions are particularly important to identify in hereditary syndromes as they are found with 2.75-fold increased frequency in familial PC cases. ${ }^{67}$

\section{PANCREATIC CYSTIC LESIONS: MCNs AND IPMNs}

IPMNs are grossly visible, noninvasive, mucin-producing epithelial neoplasms. IPMNs can be classified into three categories which include main duct IPMN (MD-IPMN), branch duct IPMN (BD-IPMN) and mixed type. ${ }^{59}$ IPMNs affect men slightly more than women and are located most frequently in the pancreatic head..$^{59,68,69}$ MD-IPMNs have a much higher incidence of malignancy ( $24 \%$ to $45 \%$ ), while BD-IPMNs are often incidental findings with a lower risk for malignancy managed with close surveillance. $^{70,71}$ Mixed type IPMN shows features of both MDIPMN and BD-IPMN. ${ }^{71}$ BD-IPMNs have been estimated to grow at an average rate of $1.1 \mathrm{~mm}$ per year; cysts that grow at a faster rate of more than $2.2 \mathrm{~mm}$ per year represent a higher risk for malignancy. ${ }^{72}$ It takes approximately 5 years from the time of development of an IPMN to progress to an invasive carcinoma. $^{73}$

MCNs are mucin-producing, cyst-forming epithelial neoplasms with distinctive ovarian-type stroma. They almost always occur in middle aged females (99.7\%) and are located predominantly in the body or tail of the pancreas $(94.6 \%) .{ }^{74}$ 
Noninvasive MCNs have a 5-year survival approaching 100\%, while invasive MCNs have a 5-year survival of 57\%. ${ }^{75}$

\section{RECOMMENDATIONS FOR SCREENING}

Widespread cancer screening programs are reserved for populations with high disease prevalence. ${ }^{76} \mathrm{PC}$ has a low population prevalence with approximately 68 out of 100,000 individuals over the age of 55 developing PC yearly ${ }^{77}$ and a lifetime risk of approximately $1.5 \%$ in the general population. ${ }^{78}$ Given this low incidence, screening for the general population is not recommended. A hypothetical scenario of 100,000 individuals in the general population using a screening test with $100 \%$ sensitivity and 98\% specificity would result in only 68 true positive test results and nearly 2,000 false positive results. This high false positive rate would lead to unnecessary, expensive and often invasive testing for individuals who have no increased risk for PC. Therefore, a current goal is to identify high risk individuals, like those with FPC or hereditary PC syndromes, who may benefit from PC screening.

As first described by Wilson and Jungner ${ }^{79}$ in 1968 , several important criteria must be met in order to consider screening for a disease: (1) the disease for which one is screening must be an important health issue; (2) precursor lesions must be recognized during a latent or early asymptomatic stage; (3) facilities for diagnosis and management of the PC must be available; (4) treatments are acceptable to patients; and (5) testing for the disease must be suitable to both the medical community and the population to be screened. Additional objectives that need to be addressed in order to achieve early detection and cure of PC include further understanding of the natural history of PC, developing consensus policies on individuals who are candidates for screening, and development of effective and cost-effective screening tools.

\section{PANCREATIC CANCER SCREENING}

At some institutions, individuals at risk for PC are considered for screening if they carry a $>5 \%$ lifetime risk of developing PC compared to the general population. ${ }^{9,76}$ In an effort to develop more concrete screening and surveillance guidelines, the International Cancer of the Pancreas Screening (CAPS) Consortium, a multidisciplinary panel of 49 experts, convened in 2011 to answer the following questions: who should be screened, how should high-risk individuals be screened and followed, and how to define success from PC screening. ${ }^{76}$ The individuals who are recommended for screening by CAPS guidelines are listed in Table 2. There was no consensus on what age to initiate screening, although a majority recommended starting at age 50 unless high risk factors are present; for example mutation in the PRSS1 gene, PJS, or individuals who smoke, all of which have well known association with earlier onset of PC. ${ }^{48,49,76}$

\section{TRADITIONAL SCREENING MODALITIES}

\section{Imaging}

Most centers consider endoscopic ultrasonography (EUS) and magnetic resonance imaging (MRI) with magnetic resonance cholangiogram (MRCP) to be the most accurate tools for pancreatic imaging. These modalities are more sensitive at detecting very small pancreatic lesions with the benefit of no ionizing radiation when compared with computed tomography (CT). ${ }^{9,76}$ MRI/MRCP is often used due to its ability to detect small cystic pancreatic lesions or abnormalities of the pancreatic duct. While MRI is noninvasive and can also detect extrapancreatic lesions, not all patients can tolerate the procedure due to claustrophobia. Furthermore, if a lesion is detected, the patient may require a confirmatory EUS. In a study of high risk individuals, EUS identified pancreatic lesions in $42.6 \%$ of participants, MRI/ MRCP in 33.3\% and CT in $11 \% .^{80}$ EUS is often favored given its ability to detect small solid or cystic lesions $<1 \mathrm{~cm} .{ }^{81}$ EUS can also be paired with fine needle aspiration in the event that sampling is necessary, with a sensitivity, specificity, and accuracy of 91\%, 100\%, and 92\%, respectively in diagnosing pancreatic malignancy. ${ }^{82}$ However, EUS requires gastroenterologists with an advanced level of training, which ultimately results in an operator dependent study with problematic predictive value. ${ }^{83}$ Furthermore, the procedure is invasive, often requiring anesthesia, with complications of endoscopy that may result in bleeding, infection, or bowel perforation. Data in high-risk individu-

Table 2. Current Cancer of the Pancreas Screening Consensus Guidelines for Pancreatic Cancer Screening

\begin{tabular}{l} 
Candidates for pancreatic cancer screening \\
\hline Individuals with $\geq 3$ affected blood relatives, at least one of who is a FDR \\
Individuals with $\geq 2$ affected FDRs with PC, with at least one affected FDR \\
Individuals with Peutz-Jeghers syndrome \\
Mutation carriers of p16, BRCA2, PALB2 with one affected FDR \\
Mutation carriers of BRCA2 with two affected family members, even if no FDRs \\
Mutation carriers of MMR (Lynch syndrome) with one affected FDR
\end{tabular}

FDR, first-degree relative; PC, pancreatic cancer. 
als suggests that EUS may be superior in detecting solid lesions, while MRI may have improved sensitivity for cystic lesions. ${ }^{80,84}$ Over-diagnosis is a major concern, particularly given the modest inter-observer agreement between imaging modalities. ${ }^{85,86}$ The result may be overtreatment of benign lesions, a grave risk when taking into account the morbidity and mortality involved in pancreatic surgery. The strengths and weaknesses of traditional screening methods are summarized in Table 3.

\section{Biomarkers}

The role of tumor markers is currently limited in the screening of asymptomatic individuals for PC. Several tumor markers have been evaluated including carbohydrate antigen 19-9 (CA 19-9) and carcinoembryonic antigen but none have proven useful as a screening modality. ${ }^{9,76}$ CA $19-9$ is a biomarker that is used in monitoring PC disease recurrence and is therefore most informative when used to measure response to adjuvant chemotherapy or in monitoring after PC resection. ${ }^{87,88}$ One study compiled data for the use of CA 19-9 screening in the general population and found a median sensitivity of 0.79 (range, 70\% to $90 \%$ ), specificity of 0.82 (68\% to $91 \%$ ), positive predictive value of 72 (41 to 95) and negative predictive value of 81 (65 to 98 ) in diagnosing PC. Based on this data, CA 19-9 as a screening test cannot be used alone confidently. ${ }^{89,90}$

\section{NEW SCREENING MODALITIES}

Pancreatic juice collected from the duodenum, has recently received interest as a potential source for biomarker measurement. Pancreatic juice is made up of a remarkably rich source of proteins that are shed by the pancreatic ductal cells. ${ }^{91}$ One study compared the proteins extracted from the pancreatic juice in patients with pancreatitis versus patients with PC; of the 72 proteins isolated, nine proteins were distinctly expressed in PC patients alone. ${ }^{92}$ Some high risk markers isolated from pancreatic juice include mutations in TP53, KRAS and guanine nucleotide binding protein alpha stimulating (GNAS). The TP53 gene has proven to be highly specific for invasive PC and high

Table 3. Strengths and Weaknesses of Current Screening and Surveillance Methods and New Methods under Development

\begin{tabular}{|c|c|c|}
\hline & Strength & Weakness \\
\hline \multicolumn{3}{|l|}{ Currently available screening method } \\
\hline \multirow[t]{2}{*}{ Computed tomography } & Rapid time interval for diagnosis & Ionizing radiation exposure \\
\hline & & Limitations with imaging small lesions \\
\hline \multirow[t]{4}{*}{ Magnetic resonance imaging } & Accurate & Over-diagnosis \\
\hline & No ionizing radiation & May have limitations in detecting small solid lesions \\
\hline & Can detect extrapancreatic lesions & Some patient have difficulty tolerating imaging test \\
\hline & Superior ability to detect small cystic lesions & \\
\hline \multirow[t]{3}{*}{ Endoscopic ultrasound } & Ability to do fine-needle aspiration & Invasive procedure \\
\hline & Superior ability to detect small solid lesion & Operator dependent \\
\hline & & Requires anesthesia \\
\hline \multirow[t]{2}{*}{ Biomarkers: CEA/CA 19-9 } & Measures progression of established disease & Not a reliable screening or surveillance tool \\
\hline & Measures response to chemotherapy & May be elevated in nonpancreatic disease \\
\hline \multicolumn{3}{|l|}{ Screening methods under development } \\
\hline Pancreatic juice (TP53, KRAS, GNAS) & $\begin{array}{l}\text { May identify specific gene mutations in } \\
\text { pancreatic cancer development }\end{array}$ & Requires endoscopic ultrasound \\
\hline \multirow[t]{3}{*}{ Stool DNA } & Noninvasive & Under development \\
\hline & & $\begin{array}{l}\text { May be a complimentary tool to other screening } \\
\text { methods }\end{array}$ \\
\hline & & Would require confirmatory testing \\
\hline \multirow[t]{3}{*}{ Methylated DNA markers } & Potential to discriminate between high-grade & Under development \\
\hline & and low-grade precursor lesions & $\begin{array}{l}\text { May be a complimentary tool to other screening } \\
\text { methods }\end{array}$ \\
\hline & & Would require confirmatory testing \\
\hline \multirow[t]{3}{*}{ MicroRNA } & Helpful diagnostic and prognostic biomarker & Under development \\
\hline & $\begin{array}{l}\text { Reasonable sensitivity and specificity for } \\
\text { tumors }\end{array}$ & $\begin{array}{l}\text { May be a complimentary tool to other screening } \\
\text { methods }\end{array}$ \\
\hline & & Would require confirmatory testing \\
\hline
\end{tabular}


grade dysplasia (HGD), found in up to $75 \%$ of invasive PCs. ${ }^{93}$ The concomitantly high proportion of PanIN-3 lesions in this population supports PanIN-3 lesions as a precursor source for TP53 mutations. ${ }^{94}$ GNAS is another well-known mutation that is highly specific for IPMNs; GNAS has been detected in approximately $64 \%$ of individuals with IPMNs and 0\% of healthy controls. $^{95}$ The prevalence of GNAS found in pancreatic juice of patients with IPMNS was similar to that isolated in resected specimens of IPMNs. ${ }^{94}$ Conversely, KRAS mutations have been isolated in more than 90\% of PanIN lesions and a majority of IPMNs and MCNs. KRAS mutations alone cannot reliably distinguish low grade precursors from HGD, as they have been seen in both invasive PCs (73\%) but also healthy controls (19\%), who likely harbor benign PanIN-1 lesions. ${ }^{94}$ See Table 3 for a summary of strengths and weaknesses of new screening methods under development.

Stool DNA is a promising, noninvasive approach used to test for DNA in the stool offering an opportunity to analyze excreted exfoliants. ${ }^{96}$ Initially for colorectal screening, this technique is being explored for PC screening. One study investigated nine targeted genes by real-time methylation specific PCR in PC cases and found that methylated BMP3 alone detected 51\% of PCs, mutant KRAS detected 50\%, and combination of the two markers detected 67\% of PCs. ${ }^{97}$ Further work in this area is required.

MicroRNA has been isolated in the serum, plasma, saliva, stool, and pancreatic juice and consists of small noncoding RNAs that are cleaved from 70 to 100 nucleotide hairpin premicroRNA precursors into mature forms of 19 to 25 nucleotides. ${ }^{98}$ Because microRNAs act as essential posttranscriptional regulators of gene expression, they are important diagnostic and prognostic markers for many solid cancers. ${ }^{99,100}$ MicroRNA distinctive to PC could serve as an important diagnostic biomarker. ${ }^{98}$ While many studies of microRNAs in PC have been performed with varying results, miR-21, miR-155, miR-196, and miR-210 have been consistently dysregulated in PC. Additional dysregulation of miR-21, miR-155, and miR-196 has also been noted in IPMNs and PanIN lesions. ${ }^{101}$ One study isolated 38 distinct microRNAs from whole blood that were found to be significantly dysregulated in patients with PC compared with healthy controls. ${ }^{102}$ Two microRNA panels were formulated, one comprising four microRNAs (miR-145, miR-150, miR-223, and miR-636) and another with 10 microRNAs (miR-26b, miR34a, miR-122, miR-126, miR-145, miR-150, miR-223, miR-505, miR-636, and miR-885.5p). These panels have shown promise as a test for stage IA-IIB PC, especially in combination with CA 19-9 with performance measured as the area under the curve (AUC) resulting in an AUC of 0.83 and 0.91 for each panel respectively. ${ }^{102}$ Later work investigating microRNA in the plasma as an adjunct to CA-19-9 distinguished PC from non-PC tissue with a sensitivity of $92.0 \%$ and specificity of $95.6 \% .^{99}$ The combined diagnostic method was most effective at diagnosing early stage 1 tumors (85.2\%) and therefore could serve as a comple- mentary tool for early PC diagnosis. ${ }^{99}$

Methylated DNA Markers have recently been used in discerning high-grade precursor lesions (IPMNs with HGD, PanIN-3, or invasive cancers) from low-grade precursor lesions (IPMNs with low grade dysplasia, PanIN-1, or PanIN-2). ${ }^{103,104}$ DNA methylation events unique to tumor type and site can be advantageous in isolating high risk pancreatic lesions. A recent study used reduced bisulfate sequencing (RRBS) on DNA from normal frozen pancreatic tissue and neoplastic tissue to identify a panel of markers (TBX15, VWC2, PRKCB, CLEC11A, EMX1, ELM01, DLX 4, ABCB1, ST8SIA1, and SP9) that had strong discrimination between high grade precursor lesions and low-grade precursor lesions with an AUC of $>0.85 .^{103,104}$ The panel detected $89 \%, 87 \%, 77 \%$, and $74 \%$ of cases at respective specificities of 85\%, 90\%, 95\%, and 100\%. ${ }^{96}$ Several of the RRBS-discovered markers have been found on genes known to be important in tumorigenesis, cell signaling, and epithelial-to-mesenchymal transition. $^{104}$

\section{CONCLUSIONS}

Although treatments of PC has improved, the survival rates remain dismal with an average 5-year survival of 7\%. Because of the low incidence of PC in the general population, population-based screening is not recommended. Therefore, recognition of high-risk individuals including those with FPC and other hereditary syndromes is imperative to identify early stages of disease. By recognizing premalignant lesions, we may identify individuals who are candidates for screening and possibly resection of early stage disease. The clinical importance of precursor lesions (PanINs and IPMNs) is becoming better understood as their natural history is defined. This further permits the application of evidence based strategies to develop guidelines for management of these lesions. Increased accessibility of genome sequencing will enable more accurate identification of high risk genes and new targeted gene therapies.

\section{CONFLICTS OF INTEREST}

No potential conflict of interest relevant to this article was reported.

\section{REFERENCES}

1. Ferlay J, Soerjomataram I, Dikshit R, et al. Cancer incidence and mortality worldwide: sources, methods and major patterns in GLOBOCAN 2012. Int J Cancer 2015;136:E359-E386.

2. Vincent A, Herman J, Schulick R, Hruban RH, Goggins M. Pancreatic cancer. Lancet 2011;378:607-620.

3. American Cancer Society. Cancer facts \& figures 2016. Atlanta: American Cancer Society, 2016.

4. Hruban RH, Canto MI, Goggins M, Schulick R, Klein AP. Update 
on familial pancreatic cancer. Adv Surg 2010;44:293-311.

5. Chari ST, Kelly K, Hollingsworth MA, et al. Early detection of sporadic pancreatic cancer: summative review. Pancreas 2015;44:693-712.

6. Bartsch DK, Gress TM, Langer P. Familial pancreatic cancer: current knowledge. Nat Rev Gastroenterol Hepatol 2012;9:445-453.

7. Ni X, Yang J, Li M. Imaging-guided curative surgical resection of pancreatic cancer in a xenograft mouse model. Cancer Lett 2012;324:179-185.

8. Bilimoria KY, Bentrem DJ, Ko CY, et al. Validation of the 6th edition AJCC pancreatic cancer staging system: report from the national cancer database. Cancer 2007;110:738-744.

9. Brand RE, Lerch MM, Rubinstein WS, et al. Advances in counselling and surveillance of patients at risk for pancreatic cancer. Gut 2007;56:1460-1469.

10. Klein AP, Brune KA, Petersen GM, et al. Prospective risk of pancreatic cancer in familial pancreatic cancer kindreds. Cancer Res 2004;64:2634-2638.

11. Klein AP, Beaty TH, Bailey-Wilson JE, Brune KA, Hruban RH, Petersen GM. Evidence for a major gene influencing risk of pancreatic cancer. Genet Epidemiol 2002;23:133-149.

12. McFaul CD, Greenhalf W, Earl J, et al. Anticipation in familial pancreatic cancer. Gut 2006;55:252-258.

13. Schneider R, Slater EP, Sina M, et al. German national case collection for familial pancreatic cancer ( $\mathrm{FaPaCa})$ : ten years experience. Fam Cancer 2011;10:323-330.

14. D'Andrea AD, Grompe M. The Fanconi anaemia/BRCA pathway. Nat Rev Cancer 2003;3:23-34.

15. Breast Cancer Linkage Consortium. Cancer risks in BRCA2 mutation carriers. J Natl Cancer Inst 1999;91:1310-1316.

16. van Asperen CJ, Brohet RM, Meijers-Heijboer EJ, et al. Cancer risks in BRCA2 families: estimates for sites other than breast and ovary. J Med Genet 2005;42:711-719.

17. Thompson D, Easton DF; Breast Cancer Linkage Consortium. Cancer incidence in BRCA1 mutation carriers. J Natl Cancer Inst 2002;94:1358-1365.

18. Brose MS, Rebbeck TR, Calzone KA, Stopfer JE, Nathanson KL, Weber BL. Cancer risk estimates for BRCA1 mutation carriers identified in a risk evaluation program. J Natl Cancer Inst 2002;94:1365-1372.

19. Moran A, O'Hara C, Khan S, et al. Risk of cancer other than breast or ovarian in individuals with BRCA1 and BRCA2 mutations. Fam Cancer 2012;11:235-242.

20. Ford D, Easton DF, Bishop DT, Narod SA, Goldgar DE. Risks of cancer in BRCA1-mutation carriers. Breast Cancer Linkage Consortium. Lancet 1994;343:692-695.

21. Rahman N, Seal S, Thompson D, et al. PALB2, which encodes a BRCA2-interacting protein, is a breast cancer susceptibility gene. Nat Genet 2007;39:165-167.

22. Tischkowitz MD, Sabbaghian N, Hamel N, et al. Analysis of the gene coding for the BRCA2-interacting protein PALB2 in familial and sporadic pancreatic cancer. Gastroenterology 2009;137:1183-
1186.

23. Jones S, Hruban RH, Kamiyama M, et al. Exomic sequencing identifies PALB2 as a pancreatic cancer susceptibility gene. Science 2009;324:217.

24. Jenne DE, Reimann H, Nezu J, et al. Peutz-Jeghers syndrome is caused by mutations in a novel serine threonine kinase. Nat Genet 1998;18:38-43.

25. van Lier MG, Wagner A, Mathus-Vliegen EM, Kuipers EJ, Steyerberg EW, van Leerdam ME. High cancer risk in Peutz-Jeghers syndrome: a systematic review and surveillance recommendations. Am J Gastroenterol 2010;105:1258-1264.

26. Tomlinson IP, Houlston RS. Peutz-Jeghers syndrome. J Med Genet 1997;34:1007-1011.

27. Giardiello FM, Brensinger JD, Tersmette AC, et al. Very high risk of cancer in familial Peutz-Jeghers syndrome. Gastroenterology 2000;119:1447-1453.

28. Goldstein AM, Chan M, Harland M, et al. Features associated with germline CDKN2A mutations: a GenoMEL study of melanomaprone families from three continents. J Med Genet 2007;44:99106.

29. Kamb A, Shattuck-Eidens D, Eeles R, et al. Analysis of the p16 gene (CDKN2) as a candidate for the chromosome 9p melanoma susceptibility locus. Nat Genet 1994;8:23-26.

30. Hussussian CJ, Struewing JP, Goldstein AM, et al. Germline p16 mutations in familial melanoma. Nat Genet 1994;8:15-21.

31. Goldstein AM, Dracopoli NC, Engelstein M, Fraser MC, Clark WH Jr, Tucker MA. Linkage of cutaneous malignant melanoma/ dysplastic nevi to chromosome 9p, and evidence for genetic heterogeneity. Am J Hum Genet 1994;54:489-496.

32. Goldstein AM, Fraser MC, Struewing JP, et al. Increased risk of pancreatic cancer in melanoma-prone kindreds with p16INK4 mutations. N Engl J Med 1995;333:970-974.

33. Kastrinos F, Stoffel EM. History, genetics, and strategies for cancer prevention in Lynch syndrome. Clin Gastroenterol Hepatol 2014;12:715-727.

34. Win AK, Young JP, Lindor NM, et al. Colorectal and other cancer risks for carriers and noncarriers from families with a DNA mismatch repair gene mutation: a prospective cohort study. J Clin Oncol 2012;30:958-964.

35. Galiatsatos P, Foulkes WD. Familial adenomatous polyposis. Am J Gastroenterol 2006;101:385-398.

36. Swift M, Chase CL, Morrell D. Cancer predisposition of ataxia-telangiectasia heterozygotes. Cancer Genet Cytogenet 1990;46:2127.

37. Roberts NJ, Jiao Y, Yu J, et al. ATM mutations in patients with hereditary pancreatic cancer. Cancer Discov 2012;2:41-46.

38. Swift M, Morrell D, Massey RB, Chase CL. Incidence of cancer in 161 families affected by ataxia-telangiectasia. N Engl J Med 1991;325:1831-1836.

39. Férec C, Raguénès 0, Salomon R, et al. Mutations in the cationic trypsinogen gene and evidence for genetic heterogeneity in hereditary pancreatitis. J Med Genet 1999;36:228-232. 
40. LaRusch J, Whitcomb DC. Genetics of pancreatitis. Curr Opin Gastroenterol 2011;27:467-474.

41. Lowenfels AB, Maisonneuve P, DiMagno EP, et al. Hereditary pancreatitis and the risk of pancreatic cancer. J Natl Cancer Inst 1997;89:442-446.

42. Pogue-Geile KL, Chen R, Bronner MP, et al. Palladin mutation causes familial pancreatic cancer and suggests a new cancer mechanism. PLoS Med 2006;3:e516.

43. Klein AP, Borges M, Griffith M, et al. Absence of deleterious palladin mutations in patients with familial pancreatic cancer. Cancer Epidemiol Biomarkers Prev 2009;18:1328-1330.

44. Jones S, Zhang X, Parsons DW, et al. Core signaling pathways in human pancreatic cancers revealed by global genomic analyses. Science 2008;321:1801-1806.

45. Slater E, Amrillaeva V, Fendrich V, et al. Palladin mutation causes familial pancreatic cancer: absence in European families. PLoS Med 2007;4:e164.

46. Ambry Genetics. PancNext [Internet]. Aliso Viejo: Ambry Genetics; c2016 [cited 2017 Jan 11]. Available from: http://www. ambrygen.com/tests/pancnext.

47. Bosetti C, Lucenteforte E, Silverman DT, et al. Cigarette smoking and pancreatic cancer: an analysis from the International Pancreatic Cancer Case-Control Consortium (Panc4). Ann Oncol 2012;23:1880-1888.

48. Rulyak SJ, Lowenfels AB, Maisonneuve P, Brentnall TA. Risk factors for the development of pancreatic cancer in familial pancreatic cancer kindreds. Gastroenterology 2003;124:1292-1299.

49. Lowenfels AB, Maisonneuve P, Whitcomb DC, Lerch MM, DiMagno EP. Cigarette smoking as a risk factor for pancreatic cancer in patients with hereditary pancreatitis. JAMA 2001;286:169170.

50. Tramacere I, Scotti L, Jenab M, et al. Alcohol drinking and pancreatic cancer risk: a meta-analysis of the dose-risk relation. Int J Cancer 2010;126:1474-1486.

51. Duell EJ. Epidemiology and potential mechanisms of tobacco smoking and heavy alcohol consumption in pancreatic cancer. Mol Carcinog 2012;51:40-52.

52. Chari ST, Leibson CL, Rabe KG, et al. Pancreatic cancer-associated diabetes mellitus: prevalence and temporal association with diagnosis of cancer. Gastroenterology 2008;134:95-101.

53. Cui Y, Andersen DK. Diabetes and pancreatic cancer. Endocr Relat Cancer 2012;19:F9-F26.

54. Gong J, Robbins LA, Lugea A, Waldron RT, Jeon CY, Pandol SJ. Diabetes, pancreatic cancer, and metformin therapy. Front Physiol 2014;5:426.

55. Bao B, Wang Z, Li Y, et al. The complexities of obesity and diabetes with the development and progression of pancreatic cancer. Biochim Biophys Acta 2011;1815:135-146.

56. Pannala R, Leirness JB, Bamlet WR, Basu A, Petersen GM, Chari ST. Prevalence and clinical profile of pancreatic cancer-associated diabetes mellitus. Gastroenterology 2008;134:981-987.

57. Huxley R, Ansary-Moghaddam A, Berrington de González A,
Barzi F, Woodward M. Type-II diabetes and pancreatic cancer: a meta-analysis of 36 studies. Br J Cancer 2005;92:2076-2083.

58. Andreotti G, Silverman DT. Occupational risk factors and pancreatic cancer: a review of recent findings. Mol Carcinog 2012;51:98-108.

59. Hruban RH, Maitra A, Kern SE, Goggins M. Precursors to pancreatic cancer. Gastroenterol Clin North Am 2007;36:831-849.

60. Distler M, Aust D, Weitz J, Pilarsky C, Grützmann R. Precursor lesions for sporadic pancreatic cancer: PanIN, IPMN, and MCN. Biomed Res Int 2014;2014:474905.

61. Basturk 0, Hong SM, Wood LD, et al. A revised classification system and recommendations from the Baltimore Consensus Meeting for neoplastic precursor lesions in the pancreas. Am J Surg Pathol 2015;39:1730-1741.

62. Sipos B, Frank S, Gress T, Hahn S, Klöppel G. Pancreatic intraepithelial neoplasia revisited and updated. Pancreatology 2009;9:4554.

63. Yachida S, Jones S, Bozic I, et al. Distant metastasis occurs late during the genetic evolution of pancreatic cancer. Nature 2010; 467:1114-1117.

64. Andea A, Sarkar F, Adsay VN. Clinicopathological correlates of pancreatic intraepithelial neoplasia: a comparative analysis of 82 cases with and 152 cases without pancreatic ductal adenocarcinoma. Mod Pathol 2003;16:996-1006.

65. Pour PM, Sayed S, Sayed G. Hyperplastic, preneoplastic and neoplastic lesions found in 83 human pancreases. Am J Clin Pathol 1982;77:137-152.

66. Cubilla AL, Fitzgerald PJ. Morphological lesions associated with human primary invasive nonendocrine pancreas cancer. Cancer Res 1976;36:2690-2698.

67. Shi C, Klein AP, Goggins M, et al. Increased prevalence of precursor lesions in familial pancreatic cancer patients. Clin Cancer Res 2009;15:7737-7743.

68. Crippa S, Fernández-Del Castillo C, Salvia R, et al. Mucinproducing neoplasms of the pancreas: an analysis of distinguishing clinical and epidemiologic characteristics. Clin Gastroenterol Hepatol 2010;8:213-219.

69. Werner J, Fritz S, Büchler MW. Intraductal papillary mucinous neoplasms of the pancreas: a surgical disease. Nat Rev Gastroenterol Hepatol 2012;9:253-259.

70. Farrell JJ, Fernández-del Castillo C. Pancreatic cystic neoplasms: management and unanswered questions. Gastroenterology 2013; 144:1303-1315.

71. Ferrone CR, Correa-Gallego C, Warshaw AL, et al. Current trends in pancreatic cystic neoplasms. Arch Surg 2009;144:448-454.

72. Kang MJ, Jang JY, Kim SJ, et al. Cyst growth rate predicts malignancy in patients with branch duct intraductal papillary mucinous neoplasms. Clin Gastroenterol Hepatol 2011;9:87-93.

73. Sohn TA, Yeo CJ, Cameron JL, et al. Intraductal papillary mucinous neoplasms of the pancreas: an updated experience. Ann Surg 2004;239:788-797.

74. Goh BK, Tan YM, Chung YF, et al. A review of mucinous cys- 
tic neoplasms of the pancreas defined by ovarian-type stroma: clinicopathological features of 344 patients. World J Surg 2006;30:2236-2245.

75. Crippa S, Salvia R, Warshaw AL, et al. Mucinous cystic neoplasm of the pancreas is not an aggressive entity: lessons from 163 resected patients. Ann Surg 2008;247:571-579.

76. Canto MI, Harinck F, Hruban RH, et al. International Cancer of the Pancreas Screening (CAPS) Consortium summit on the management of patients with increased risk for familial pancreatic cancer. Gut 2013;62:339-347.

77. Wolfgang CL, Herman JM, Laheru DA, et al. Recent progress in pancreatic cancer. CA Cancer J Clin 2013;63:318-348.

78. Howlader N, Noone AM, Krapcho M, et al. SEER cancer statistics review, 1975-2012 [Internet]. Bethesda: National Cancer Institute; c2015 [cited 2017 Jan 11]. Available from: http://seer.cancer.gov/ csr/1975_2012/.

79. Wilson JM, Jungner G. Principles and practice of screening for disease. Geneva: World Health Organization, 1968.

80. Canto MI, Hruban RH, Fishman EK, et al. Frequent detection of pancreatic lesions in asymptomatic high-risk individuals. Gastroenterology 2012;142:796-804.

81. Kimmey MB, Bronner MP, Byrd DR, Brentnall TA. Screening and surveillance for hereditary pancreatic cancer. Gastrointest Endosc 2002;56:S82-S86

82. Raut CP, Grau AM, Staerkel GA, et al. Diagnostic accuracy of endoscopic ultrasound-guided fine-needle aspiration in patients with presumed pancreatic cancer. J Gastrointest Surg 2003;7:118126.

83. Chang MC, Wong JM, Chang YT. Screening and early detection of pancreatic cancer in high risk population. World J Gastroenterol 2014;20:2358-2364.

84. Harinck F, Konings IC, Kluijt I, et al. A multicenter comparative prospective blinded analysis of EUS and MRI for screening of pancreatic cancer in high-risk individuals. Gut 2016;65:15051513.

85. Al-Sukhni W, Borgida A, Rothenmund H, et al. Screening for pancreatic cancer in a high-risk cohort: an eight-year experience. J Gastrointest Surg 2012;16:771-783.

86. Topazian M, Enders F, Kimmey M, et al. Interobserver agreement for EUS findings in familial pancreatic-cancer kindreds. Gastrointest Endosc 2007;66:62-67.

87. Fong ZV, Winter JM. Biomarkers in pancreatic cancer: diagnostic, prognostic, and predictive. Cancer J 2012;18:530-538.

88. Datta J, Vollmer CM Jr. Investigational biomarkers for pancreatic adenocarcinoma: where do we stand? South Med J 2014;107:256-263.

89. Steinberg W. The clinical utility of the CA 19-9 tumor-associated antigen. Am J Gastroenterol 1990;85:350-355.

90. Goonetilleke KS, Siriwardena AK. Systematic review of carbohy- drate antigen (CA 19-9) as a biochemical marker in the diagnosis of pancreatic cancer. Eur J Surg Oncol 2007;33:266-270.

91. Chen R, Pan S, Yi EC, et al. Quantitative proteomic profiling of pancreatic cancer juice. Proteomics 2006;6:3871-3879.

92. Chen R, Pan S, Cooke K, et al. Comparison of pancreas juice proteins from cancer versus pancreatitis using quantitative proteomic analysis. Pancreas 2007;34:70-79.

93. Kanda M, Sadakari Y, Borges M, et al. Mutant TP53 in duodenal samples of pancreatic juice from patients with pancreatic cancer or high-grade dysplasia. Clin Gastroenterol Hepatol 2013;11:719730.

94. Eshleman JR, Norris AL, Sadakari Y, et al. KRAS and guanine nucleotide-binding protein mutations in pancreatic juice collected from the duodenum of patients at high risk for neoplasia undergoing endoscopic ultrasound. Clin Gastroenterol Hepatol 2015;13:963-969.

95. Kanda M, Knight S, Topazian M, et al. Mutant GNAS detected in duodenal collections of secretin-stimulated pancreatic juice indicates the presence or emergence of pancreatic cysts. Gut 2013;62:1024-1033.

96. Osborn NK, Ahlquist DA. Stool screening for colorectal cancer: molecular approaches. Gastroenterology 2005;128:192-206.

97. Kisiel JB, Yab TC, Taylor WR, et al. Stool DNA testing for the detection of pancreatic cancer: assessment of methylation marker candidates. Cancer 2012;118:2623-2631.

98. Bloomston M, Frankel WL, Petrocca F, et al. MicroRNA expression patterns to differentiate pancreatic adenocarcinoma from normal pancreas and chronic pancreatitis. JAMA 2007;297:19011908.

99. Liu J, Gao J, Du Y, et al. Combination of plasma microRNAs with serum CA19-9 for early detection of pancreatic cancer. Int J Cancer 2012;131:683-691.

100. Bartel DP. MicroRNAs: genomics, biogenesis, mechanism, and function. Cell 2004;116:281-297.

101. Hernandez YG, Lucas AL. MicroRNA in pancreatic ductal adenocarcinoma and its precursor lesions. World J Gastrointest Oncol 2016;8:18-29.

102. Schultz NA, Dehlendorff C, Jensen BV, et al. MicroRNA biomarkers in whole blood for detection of pancreatic cancer. JAMA 2014;311:392-404.

103. Majumder S, Taylor WR, Yab TC, et al. Detection of pancreatic high-grade dysplasia and cancer using novel methylated dna markers: discovery and tissue validation. Gastroenterology 2016;150(4 Suppl 1):S120-S121.

104. Kisiel JB, Raimondo M, Taylor WR, et al. New DNA methylation markers for pancreatic cancer: discovery, tissue validation, and pilot testing in pancreatic juice. Clin Cancer Res 2015;21:44734481. 